\begin{tabular}{|c|c|c|}
\hline PORT SAID ENGINEERING RESEARCH JOURNAL \\
Faculty of Engineering - Port Said University \\
Volume 16 No. $1 \mathrm{pp:} 12: 23$
\end{tabular}

\title{
EXPERIMENTAL AND THEORETICAL STUDY OF THE EFFECT OF SECONDARY AIR DIRECTION ON NATURAL GAS DIFFUSION FLAME
}

\author{
Ibrahim A. , Nasser Shelil ${ }^{a}$, EZZ El-Dien A. $H^{a}$, M. Mosleh ${ }^{b}$ and Farag T. M. ${ }^{a}$ \\ ${ }^{a}$ Mechanical Power Engineering Dept, Faculty of Engineering, Port-Said University, Egypt \\ ${ }^{\mathrm{b}}$ Dept. of Naval Architecture \& Marine Engineering, Faculty of Engineering., Alexandria University, Egypt
}

\begin{abstract}
The aim of the present paper is to study experimentally and theoretically the natural gas flame characteristics using different secondary air inlet directions for different primary air swirl numbers and different primary air to fuel ratios. Secondary air was introduced into the combustion chamber in four directions; normal, forward, backward and tangential relative to the chamber axis and the main flow direction. For this study, a test rig was constructed including a vertical test combustor with an air swirler. It also includes primary air, secondary air and fuel lines. Four air swirlers were used changeably. These swirlers have different vane angles of $15^{\circ}, 30^{\circ}, 45^{\circ}$, and $60^{\circ}$ to generate different swirl numbers of $0.23,0.5,0.87$ and 1.5 , respectively. In addition to the base test combustor, four combustors were constructed to ensure the introduction of secondary air in four directions. During tests, the primary air mass flow rate was kept constant, while the fuel mass flow rate was changed to give different primary air/fuel ratios of 30,40 and 50. Also, the secondary air flow rate was changed to give different secondary/primary air ratios of $0.25-1$. A three dimensional model was used to simulate the turbulent reacting flow using computational fluid dynamics package (Fluent 6.3). The comparison between the measured and calculated temperature distribution shows a good agreement. Also, the results show that the introducing of secondary air leads to a decrease in the flame size, and tangential direction gives the shortest flame length for most cases while backward direction gives the longest one. Normal and forward directions produces higher $\mathrm{O}_{2}$ and lower $\mathrm{CO}$ and $\mathrm{CO}_{2}$ concentrations.
\end{abstract}

Keywords: Gas turbine combustor, Swirl number, Air to fuel ratio, Secondary air direction. Secondary to primary air ratio. *Corresponding author. E-mail address: enfarag1611@yahoo.com.

\section{ABBREVIATIONS}

A/F Primary air to fuel mass ratio

S Primary air swirl number

SPAR Secondary to primary air mass ratio

RFZ Reverse flow zone

$\mathrm{r} / \mathrm{R} \quad$ Dimensionless radial distance

$\mathrm{x} / \mathrm{D} \quad$ Dimensionless axial distance

\section{INTRODUCTION}

Researches of the combustion process such as occurring in gas turbine engines focus on clean emissions, low liner wall temperature, uniform exit temperature and fuel economy. Many parameters such as swirl number, equivalence ratio, and combustor geometry affect the combustion characteristics. These combustion characteristics including flow aerodynamics, flame stability, temperature distributions, and exhaust species concentrations have been extensively studied [1-7]. Flame stabilization has been one of the critical issues in gas turbine engines. The flame has to be anchored at a zone within the gas turbine combustor. The most commonly method used to stabilize flames is swirl stabilization in which a swirl velocity is imparted to the flow using airswirlers. The degree of swirl is quantified by the swirl number which is defined as the ratio of the tangential momentum flux to the axial momentum flux [4].

In strongly swirling flows, a recirculation zone is created in the centre of the flow which provides sufficient time, temperature and turbulence for complete combustion of the fuel with air $[4,5]$. Swirl also has other benefits to combustion system such as promoting mixing of fuel and air and assisting the control of combustion temperatures and emissions. In addition, a shorter flame was generated 
with the presence of swirl indicating good mixing [6]. Studies were performed by Chigier N. A. [7] on the effect of the swirl number on the combustion characteristics. $\mathrm{He}$ stability. Also, the effect of swirl strength on $\mathrm{NO}_{\mathrm{x}}$ formation was investigated by Claypole and Syred [8]. At swirl number of 3 , much $\mathrm{NO}_{\mathrm{x}}$ in the exhaust was recirculated back to the flame front.

The combustion of gaseous fuels in gas turbine combustors is highly complex. It includes hot gas recirculation, energy exchange and strong turbulencechemistry interactions. Therefore, the computational fluid dynamics (CFD) represents an economic and reliable tool for facilitating the combustion system design. Flame stability and pollutant emissions depend on aerodynamics and mixing characteristics of the fuel and combustion air as reported by German and Mahmud [9]. Their results showed good agreement between measurements and predictions by both the $\mathrm{k}-\varepsilon$ model and Reynold Stress model (RSM). However, some features of the combustion flow were better predicted by the RSM model as shown by Jones and Kakhi [10].

In addition to the effect of the primary air swirl, the flow field and the combustion process inside a gas turbine combustor is affected by the shape, size and arrangement of secondary air entries. The advantages of introducing secondary air are its ability to improve the flame stability, to minimize the flame size and to reduce the exhaust species concentrations. [11]. Detailed measurements of species concentrations, temperature and velocity distributions within a combustor model were performed by Abou-Arab et al. [12], with and without using secondary air. A central tube was used for natural gas admission while the combustion air flowed through an outer swirler with different vane angles of $\left(0-70^{\circ}\right)$. They found that, the turbulent reaction rate increases remarkably with introducing the secondary air and decreases with the increase of the equivalence ratio.

An experimental study was performed by Gad et al. [11] in an attempt to improve the kerosene spray combustion by introducing secondary air normal to the main flow. The effects of swirl number, air to fuel ratio and secondary to primary air ratio on the flame characteristics were investigated. Increasing the secondary to primary air ratio leads to a decrease of $\mathrm{CO}$ and $\mathrm{NO}$ and increase of $\mathrm{CO}_{2}$ concentrations.

The effect of primary air side-inlet angle on the fuel/air mixing inside a three-dimensional combustor was investigated by Ko T. H. [13]. The primary air side-inlet angle takes the values of $30^{\circ}, 60^{\circ}$ and $90^{\circ}$ to examine its concluded that the swirling flow could stabilize the combustion process and improve the mixing of fuel and air as well, swirl flow affected the flame length, size and effects on the flow field and fuel/air mixing. The results exhibit that the flow features inside the test combustor including the recirculation zone structure are significantly influenced by the primary air side-inlet angle. Also, the effect of secondary air inlet direction on the kerosene spray combustion was investigated by Gad et al.[14].

Secondary air was introduced into the combustion chamber in four directions; normal, forward, backward and tangential directions. The esults show that flame stability is improved by increasing the secondary/primary air ratio for normal, forward and tangential directions but it is decreased for backward direction.

From the previous literature studies, it is clear that most of the studies deals with the swirling effect and the mixing process. There is not enough data about the effect of the secondary air entrance direction on the combustion characteristics inside a gas turbine combustor. Few results are available in this field in particular when burning natural gas. The study of secondary air is essential for the flow field and the combustion characteristics.

In the present study, the effect of the secondary air entrance direction for different primary air swirl numbers and different secondary/primary air ratios on natural gas combustion characteristics are studied experimentally and theoretically. To validate the calculations, results of the combustion simulation are compared with the experimental data. The effect of different secondary air directions, normal, forward, backward and tangential directions on natural gas combustion characteristics are studied. The swirl number takes the values of $0.23,0.5,0.87$ and 1.5 . The effect of secondary air direction on the axial and radial temperature distributions, the flame length and the centerline species concentrations inside the test combustor are investigated.

\section{EXPERIMENTAL TEST RIG}

For the present study, a test rig was constructed including a test combustor with an air swirler at its upstream. It also includes primary air, secondary air and fuel lines. The combustor and burner assembly is shown in Fig. 1. A cylindrical water cooled vertical combustor of 20 $\mathrm{cm}$ diameter and $100 \mathrm{~cm}$ length was used to burn natural gas with air. The outer jacket is a cylindrical steel tube of $25 \mathrm{~cm}$ diameter. Two separate air blowers were used for supplying the primary air and secondary air. The primary air is issued from an air blower and enters the combustor 
through air swirler. The secondary air is issued from another air blower and enters into the combustor via flexible hoses connected to the secondary air inlets at the combustor periphery as shown in Fig. 1 Calibration curves were constructed for the air mass flow rate against the

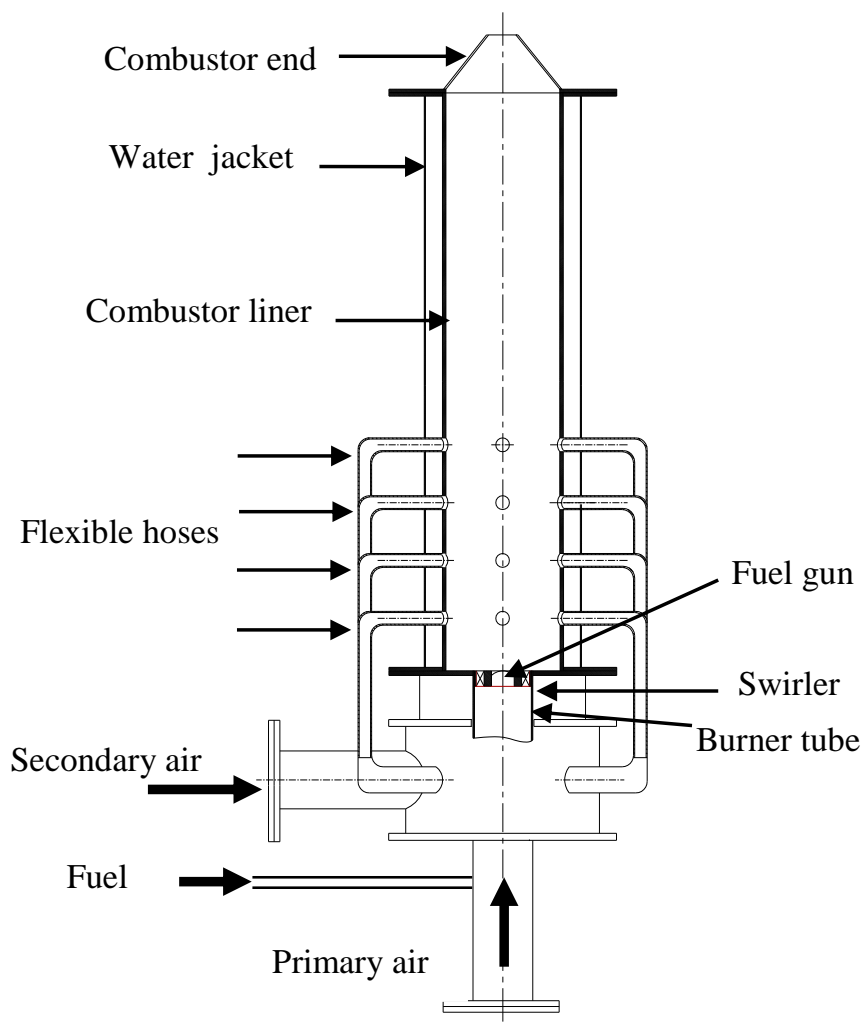

Fig. 1 Combustor and burner assembly water head difference in the manometer.

The fuel used in this study is natural gas which is stored in steel bottles at high pressure of about 200 bars. The fuel flows from the fuel bottle and enters the combustor through a fuel gun located at the center of the air swirler. A pressure regulator is used to adjust and regulate the natural gas flow rate. The natural gas volume flow rate is measured by a natural gas rotameter. Then the natural gas fuel mass flow rate is calculated using the measured fuel flow rate, fuel pressure and temperature. To keep the fuel mass flow rate nearly constant during the experimental running, two natural gas bottle with two pressure regulators were used. Five combustors were constructed for the present study. A base combustor was constructed without secondary air inlets and four combustors have secondary air inlets with different directions. Secondary air inlets are arranged in four rows at equal distance of 10 $\mathrm{cm}$ apart and each row has four inlets. Figure 2 shows the schematic drawings of the combustors used in the present study. Each combustor is equipped with measuring ports arranged in line along the combustor length to allow the introduction of the measuring probes and also for visual observation of the flame. The measuring ports are of 1.6 $\mathrm{cm}$ inner diameter and $10 \mathrm{~cm}$ length. 


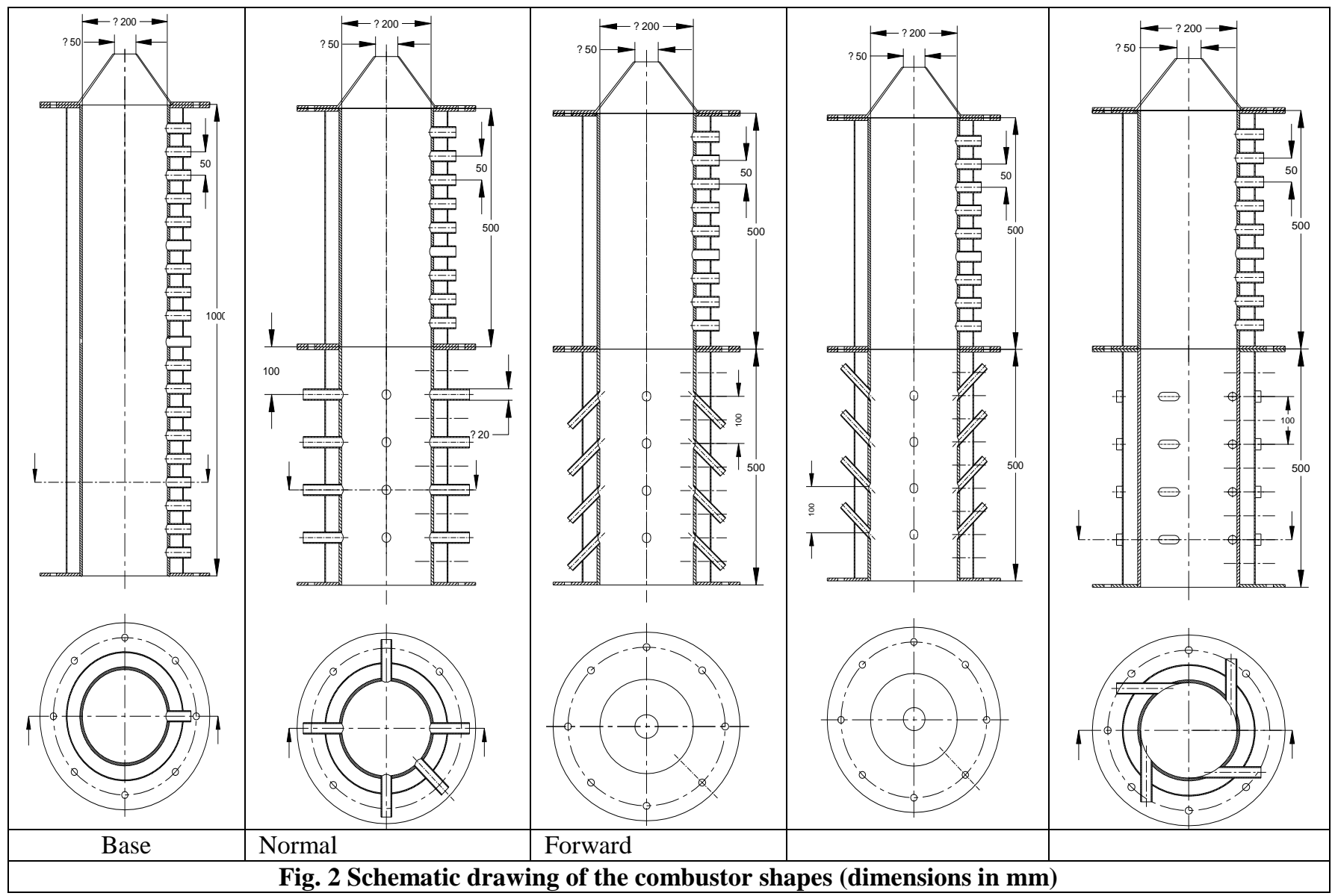

A concentric burner is fitted axially at the combustor upstream in which different air swirlers are mounted at its outlet. The burner includes a tube of $10 \mathrm{~cm}$ inner diameter, inside which air swirler is fitted axially as shown in Fig. 1. The fuel gun (nozzle) is fitted co-axially with the air swirler at the combustor entrance.

During tests, the primary air mass flow rate was kept constant at $20 \mathrm{~g} / \mathrm{s}$, while the fuel mass flow rate was changed to provide the required air/fuel mass ratios of 30 , 40 and 50. Also, the secondary air flow rate was changed to provide different secondary/primary air ratios of 0.25 1.0. The flame temperatures were measured using a bare wire $\mathrm{Pt}-\mathrm{Pt} / \mathrm{Rh}(13 \%)$ thermocouple type $\mathrm{R}$. The temperature distributions inside the combustor, the visible flame lengths and the exhaust species concentrations are investigated. The temperatures were measured radially at different axial distances through the measuring ports. From the radial and axial temperature distributions, temperature maps could be drawn for different operating conditions. The temperature map is described by temperature ranges; each range of temperature is described by a certain color.

\section{3- CFD SIMULATIONS}

CFD software gives the power to simulate flows, heat and mass transfer and chemical reactions [15]. This provides data which help in predicting the performance of the designed model. In this study, the turbulent reacting flow was simulated using the CFD code fluent 6.3 [16]. The model geometries and meshes were generated for each swirl number using Gambit 2.3 [17]. Meshes of tetrahedral cells were created, the mesh has different cell sizes according to the regions of importance. Regions of interest are volumes between swirl vanes, regions near the burner, regions near walls and secondary air inlets as shown in Fig. 3. Figure 3 shows the complete mesh of the base combustor model constructed with swirl vane angles of $45^{\circ}$ and details of the important regions such as the swirler and secondary air inlets for different direction. Numerical accuracy can be improved by careful distribution of the grid nodes which offers a good compromise between the computational time and the numerical accuracy. 
Boundary conditions were defined as mass flow inlet for primary air and fuel and velocity inlet for secondary air, based on the experimental data. The pressure outlet is used as an exit boundary condition as shown in Fig. 3. For tetrahedral meshes, the first order discretization scheme is recommended [16] and it is used in the present study.

Fluent uses a control-volume-based technique to convert a scalar transport equation to an algebraic equation to solve numerically. The flow was assumed to be incompressible and turbulent. A steady state pressure based solver is used to solve the governing equations. In the gradient option, the node-based is selected which is suitable for tetrahedral meshes. The Semi Implicit Method for Pressure Linked Equation algorithm was used for the pressure/velocity coupling which satisfies the mass conservation equation. The pressure staggering option (Presto), is selected for the discretization scheme for pressure. The Presto scheme is available for all mesh types. When using the pressurebased solver, presto is recommended as the discretization method for solving pressure [16].

For turbulence modeling, the shear-stress transport (SST) $\mathrm{k}-\omega$ model in fluent is preferred here because the level of agreement of the results for the SST k- $\omega$ model and the experimental data is better than that for other models. For modeling the reacting flow, the non premixed combustion model is selected. A probability density function (PDF) table was created which contains information on the thermo-chemistry and its interaction with turbulence. Fuel and oxidizer compositions are specified in the PDF table. All thermodynamic data, including density, specific heat, and formation enthalpies are extracted from the chemical database when the non premixed combustion model is used. The P1 model, one of the radiation models available in Fluent package 6.3, is selected for the present simulation which can produce an acceptable solution than other models with the non premixed combustion model.

To obtain a grid-independent solution, the grid should be refined until the solution no longer varies with additional cells. A grid independence test has been carried out, considering the computational expense and time, with cell numbers of 175000, 225000, 300000 and 400000. The solution of the centerline temperature distribution was performed for meshes with different cell sizes. There is a good agreement of the centerline temperature profiles for 300000 and 400000 mesh sizes while there was a higher error in the other cases. Therefore, the mesh size of 300000 cells can provide grid independent and accurate solutions. The grid with 300000 cells is considered for further analysis since the flow parameters are found to be independent of the mesh size. The solution control parameters and under-relaxation factors were properly set. For evaluating whether convergence has been reached, one method is when the residuals have decreased to a sufficient degree. Each residual will be reduced to a value less than $10^{-3}$ except for energy residual which is reduced to $10^{-6}$. 


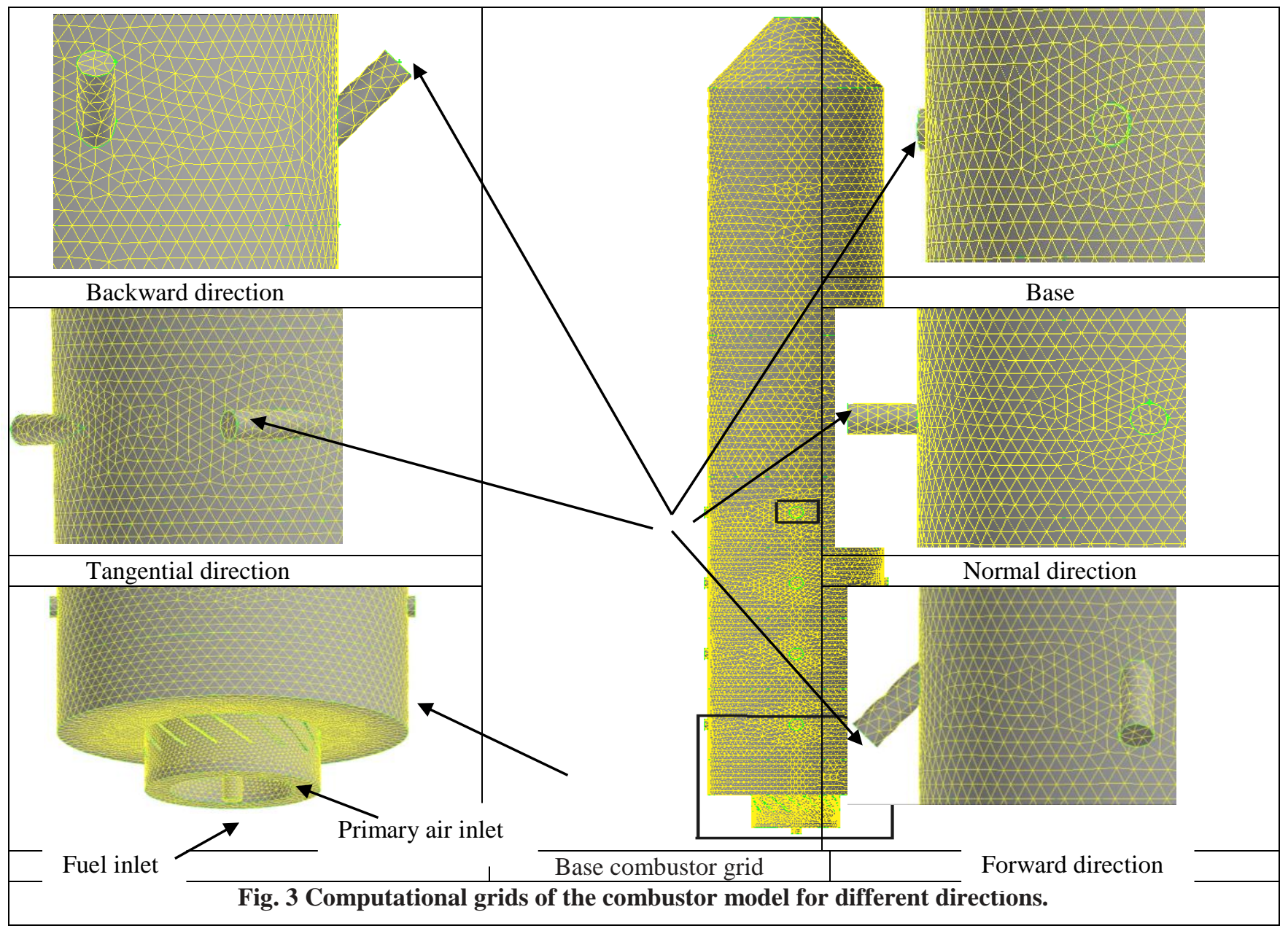

\section{RESULTS AND DISCUSSION}

\subsection{Validation of the models}

The centerline temperature distributions for different secondary air directions at swirl number of $0.87, \mathrm{~A} / \mathrm{F}$ ratio of 40 and SPAR=1 [computational and experimental] are shown in Fig.4. The centerline temperature distributions from computations are compared with that from the measured flame temperatures for validation of the models used. Comparing the results obtained from the computations and the experiments, a good agreement is found. It is seen that the temperatures from computations are higher than that from the experiments for all cases. This is due to the combustor is cooled with water which absorbs quantitative heat and further heat is lost by convection and radiation [18]. In addition, the use of bare wire thermocouple where its junction does not obtain the same temperature of the combustion gases, the measured temperature is quite far from the calculated one [19]. Generally, it is found that the measured temperature is lower than the calculated one by about $6-8 \%$.

\subsection{Axial Temperature Distribution}

Flame characteristics represented by temperature distributions, flame lengths and species concentrations are investigated for different conditions. Due to the good agreement obtained between the measured and the calculated temperature distributions, the computational results are discussed and presented in the following section. The effect of introducing the secondary air on the centerline temperature distribution at $\mathrm{A} / \mathrm{F}$ ratio $=30$, and swirl number of 1.5 for normal direction is shown in Fig. 5. It is seen that there is no effect of secondary air near the combustor upstream at axial distance of $(0 \leq x / D \leq 1)$. At further axial distance $(1 \leq \mathrm{x} / \mathrm{D} \leq 2)$ near the locations of introducing the secondary air, the temperature levels increase with introducing the secondary air and they further increase with increasing the value of SPAR. This is due to the improvement in combustion due to the direct effect of secondary air. At the combustor downstream $(2 \leq x / D \leq 5)$, there is a decrease in the temperature due to the dilution effect of the secondary air. Also, the temperature decreases with increasing the value of SPAR. 

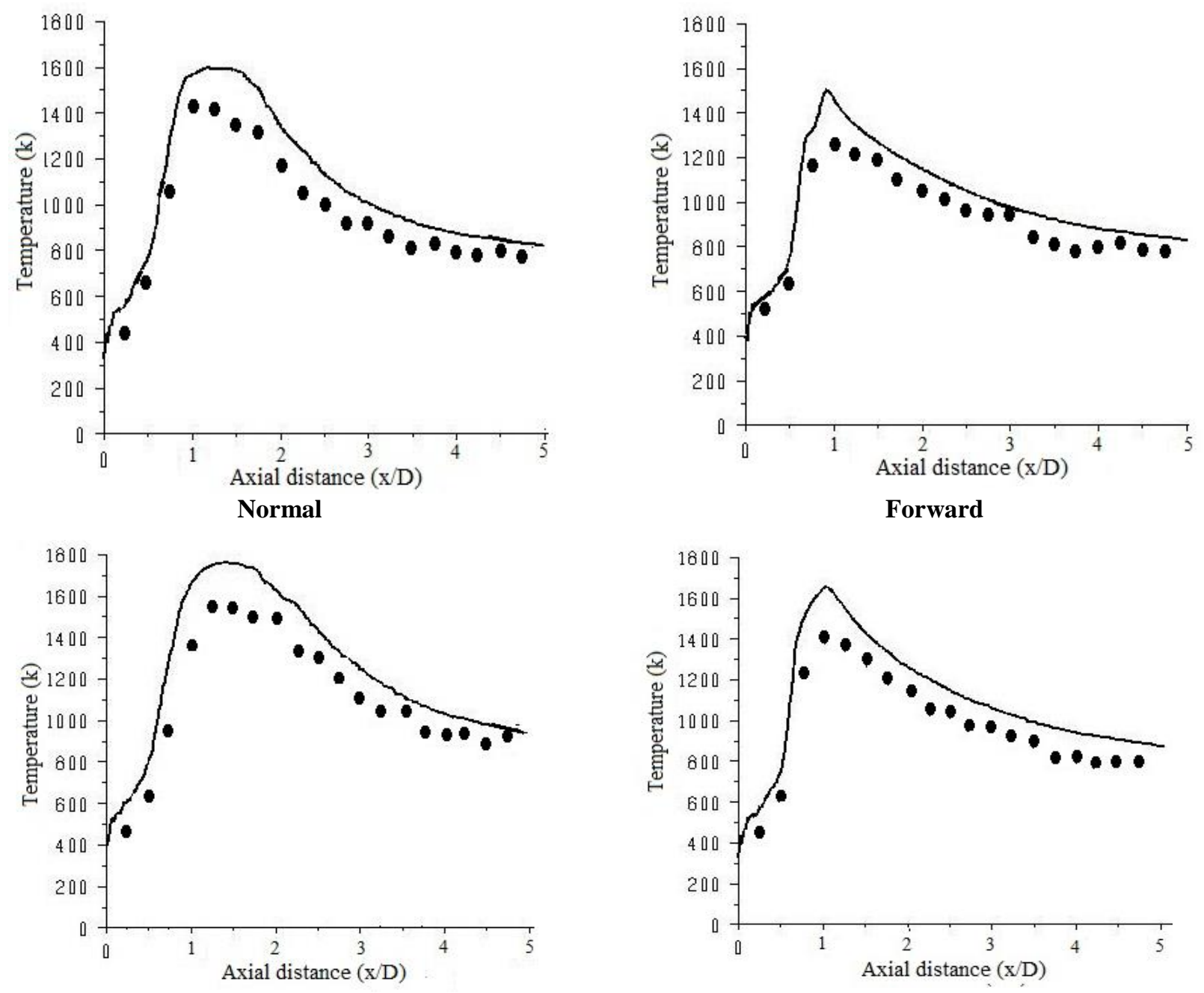

Backward

Computational

Tangential

Experimental $\longrightarrow$

Fig. 4 Centerline temperature distributions for different directions at $S=0.87, A / F=40$ and $S P A R=1$

[Computational and Experimental]

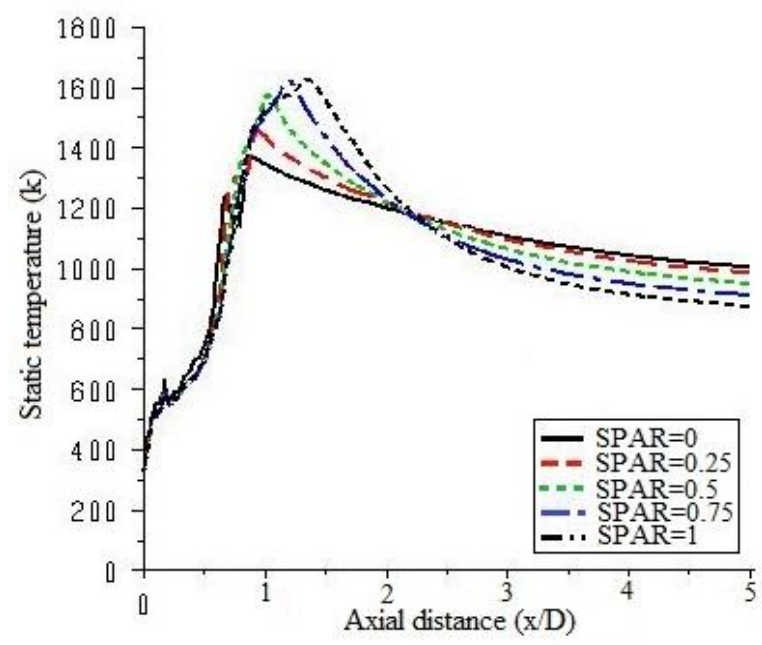

Fig. 5 Effect of SPAR on centerline temperature distribution for $\mathrm{A} / \mathrm{F}$ ratio of 30 and swirl number of 1.5 [Normal direction]
Also, the effect of secondary air direction on the centerline temperature distributions for swirl number of $0.87, \mathrm{~A} / \mathrm{F}$ ratio of 40 and SPAR of unity [computational] is shown in Fig. 6. Also, in this case, there is no effect of secondary air near the combustor upstream at axial distance of $(0 \leq x / D \leq 1)$. Introducing the secondary air leads to an increase in temperatures at axial distance of $(1 \leq \mathrm{x} / \mathrm{D} \leq 2.25)$ near the locations of introducing the secondary air for normal and tangential directions due to the improvement in combustion. For backward direction, the temperature increased at longer axial distance $(1 \leq \mathrm{x} / \mathrm{D} \leq 4)$. For forward direction, the temperature decreases along most of the combustor. At the combustor downstream $(2.25 \leq \mathrm{x} / \mathrm{D} \leq 5)$, the temperatures decrease for normal and tangential directions. The use of secondary air leads to a decrease in the exit temperature and the minimum exit temperature is obtained for normal and forward directions. 


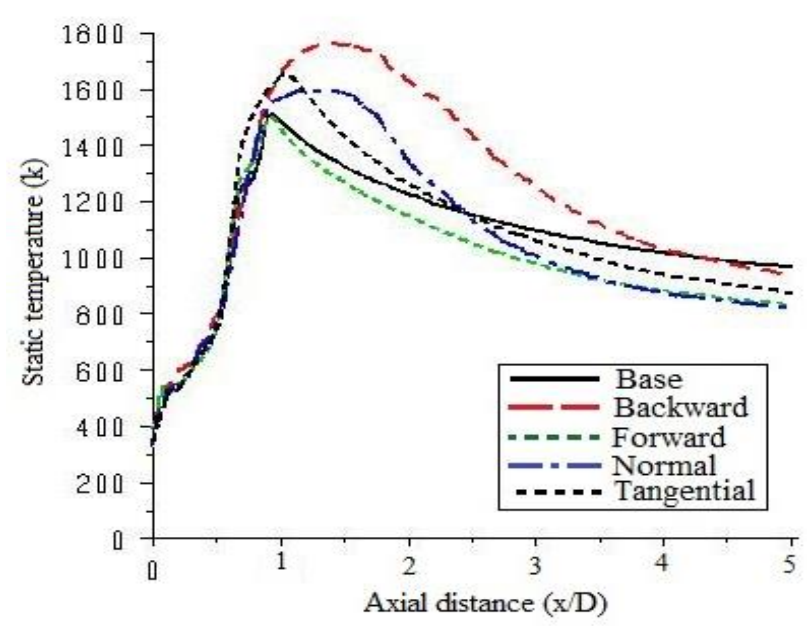

Fig. 6 Effect of secondary air direction on centerline temperature distributions for $\mathrm{A} / \mathrm{F}$ ratio of 40 , swirl number of 0.87 and SPAR=1 [Computational]

\subsection{Temperature Maps}

The effect of secondary air direction on the temperature maps at different $\mathrm{A} / \mathrm{F}$ ratios and different swirl numbers is discussed in this section. The effect of secondary air direction on temperature distributions is presented in two main cases: Case one, for large size flame $(\mathrm{A} / \mathrm{F}=30)$ at both weak swirl $(\mathrm{S}=0.5)$ and strong swirl $(\mathrm{S}=1.5)$, and case two, for small size flame $(\mathrm{A} / \mathrm{F}=50)$ at both weak swirl $(\mathrm{S}=0.23)$ and strong swirl $(\mathrm{S}=0.87)$ as shown in Figs. 7, 8, 9 , and 10, respectively. The temperature maps at SPAR $=0$ are presented at each figure for comparison.

At $\mathrm{A} / \mathrm{F}$ ratio of 30 and swirl number of 0.5 , the temperature levels are high, for SPAR $=0$, two regions of high temperature are found at radial and axial distances of $0.3 \leq \mathrm{x} / \mathrm{D} \leq 0.7$ and $0.5 \leq \mathrm{x} / \mathrm{D} \leq 2.25$, respectively. Introducing secondary air $[\mathrm{SPAR}=1]$, the temperature levels for all directions are slightly affected while the regions of high temperature varied according to the directions as shown in Fig. 7. In this figure, it is shown that when using the secondary air, the flame diameter decreases while the flame length is nearly the same for all directions. For forward direction, two regions of high temperature are found while one region of high temperature is formed for other directions. The region of high temperature are found at axial distance of $0.25 \leq \mathrm{x} / \mathrm{D} \leq 3, \quad 0.25 \leq \mathrm{x} / \mathrm{D} \leq 2.5$, $0.25 \leq \mathrm{x} / \mathrm{D} \leq 3.5, \quad 0.25 \leq \mathrm{x} / \mathrm{D} \leq 2.5$ for normal, forward, backward and tangential directions, respectively. For backward direction, the flame diameter decrease at upstream and increase at downstream and a high temperature region of large size is found. For tangential direction, the high temperature region becomes shorter but wider in diameter. Thus, it is seen that for low $\mathrm{A} / \mathrm{F}$ ratio and weak swirl (flame of large size) there are slight change in flame sizes for different directions as seen in Fig. 7.

Using the same air/fuel ratio of 30 but with swirl number of 1.5 , the temperature levels become lower than that of the previous case due to the strong swirl. For SPAR $=0$, two high temperature regions are formed at axial distance of $0.1 \leq \mathrm{x} / \mathrm{D} \leq 1$ and the region of low temperature is nearly disappeared as shown in Fig. 8. Introducing the secondary air, two high temperature regions are formed for forward and tangential directions at axial distance of $0.1 \leq \mathrm{x} / \mathrm{D} \leq 1$. For normal and backward directions, one region of high temperature is found at $0.1 . \leq x / D \leq 1.5$ and $0.1 \leq x / D \leq 1.75$ respectively. The temperature levels are remarkably decreased when using the secondary air for all directions except for the backward one as shown in Fig 8. The flame diameter is narrow for normal direction while it is wider for forward one. The backward direction has the larger size of the high temperature region. Introducing the secondary air, leads to different temperature levels and different flame sizes due to the directions. The temperature levels and consequently the flame sizes decrease remarkably for normal and forward directions while the tangential direction has smaller size than that of the backward one.

At $\mathrm{A} / \mathrm{F}$ ratio of 50 and swirl number of 0.23 , the temperature levels are low despite the weak swirl because of the high $\mathrm{A} / \mathrm{F}$ ratio. For SPAR=0, two high temperature regions are found at axial distance of $0.5 \leq \mathrm{x} / \mathrm{D} \leq 1.25$ as shown in Fig. 9. Under this condition, the temperature levels decreased remarkably when introducing the secondary air for all directions. The high temperature regions are found at $0.25 \leq \mathrm{x} / \mathrm{D} \leq 1.5, \quad 0.25 \leq \mathrm{x} / \mathrm{D} \leq 1.25$, $0.5 \leq \mathrm{x} / \mathrm{D} \leq 3,0.25 \leq \mathrm{x} / \mathrm{D} \leq 2$ for normal, forward, backward and tangential directions, respectively. For the forward direction, two high temperature regions are found. The temperature levels are remarkably lower. For normal direction than others. For backward direction, the flame has longer length and smaller diameter. For tangential direction, the temperature levels are relatively high and the high temperature region is large due to the lower swirling effect of weak swirl as shown in Fig. 9.

Using the same $\mathrm{A} / \mathrm{F}$ ratio of 50 but with strong swirl of swirl number $=0.87$, the temperature levels are low and the flame length is small due to the high $\mathrm{A} / \mathrm{F}$ ratio as shown in Fig. 10. Introducing secondary, the temperature levels and the flame sizes are clearly decreased for all directions. The temperature levels and the high temperature regions differ clearly with the different directions. Tangential direction gives the smallest flame size. 

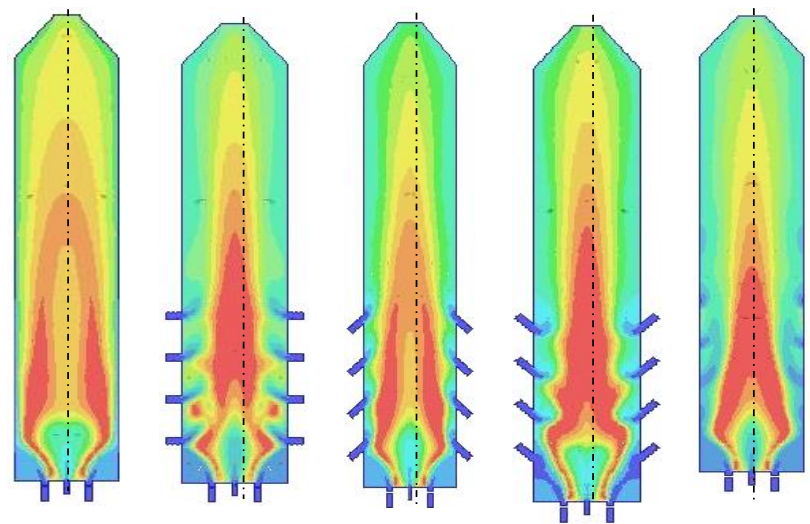

Base
Forward
Backward
Tangent. $560 \quad 1700$

Fig. 7 Effect of secondary air direction on temperature maps from calculations $[\mathrm{S}=\mathbf{0 . 5}, \mathrm{A} / \mathrm{F}$ ratio $=30$ and $S P A R=1$ ]
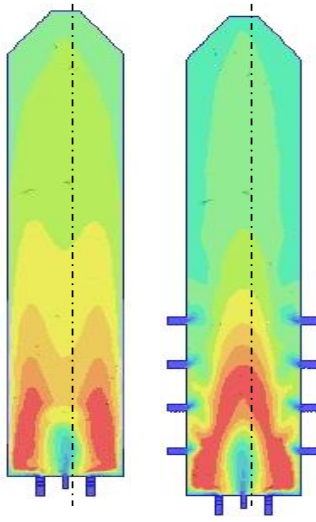

Base

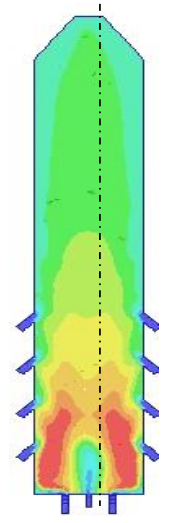

Forward

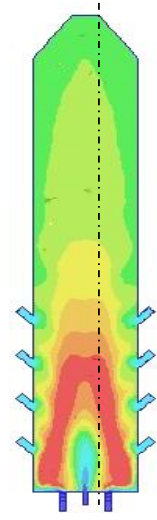

Backward

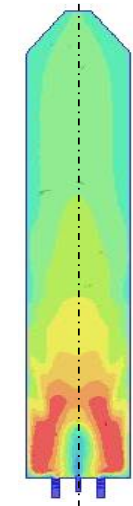

Tangent.

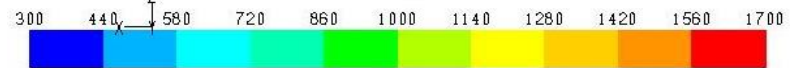

Fig. 8 Effect of secondary air direction on temperature. maps from calculations $[S=1.5, A / F$ ratio $=30$ and $S P A R=1$

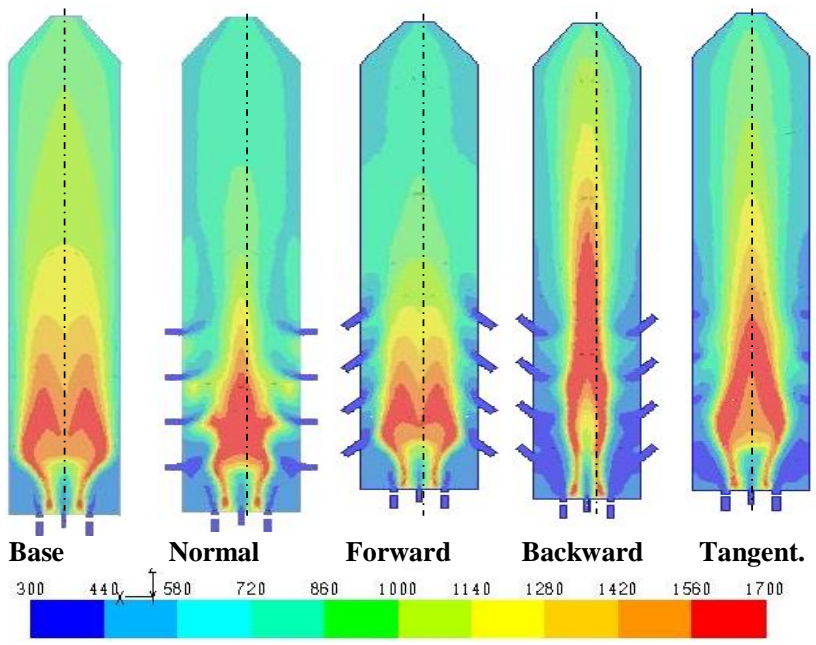

Fig. 9 Effect of secondary air direction on temperature. maps from calculations[S=0.23, $A / F$ ratio=50 and $S P A R=1]$
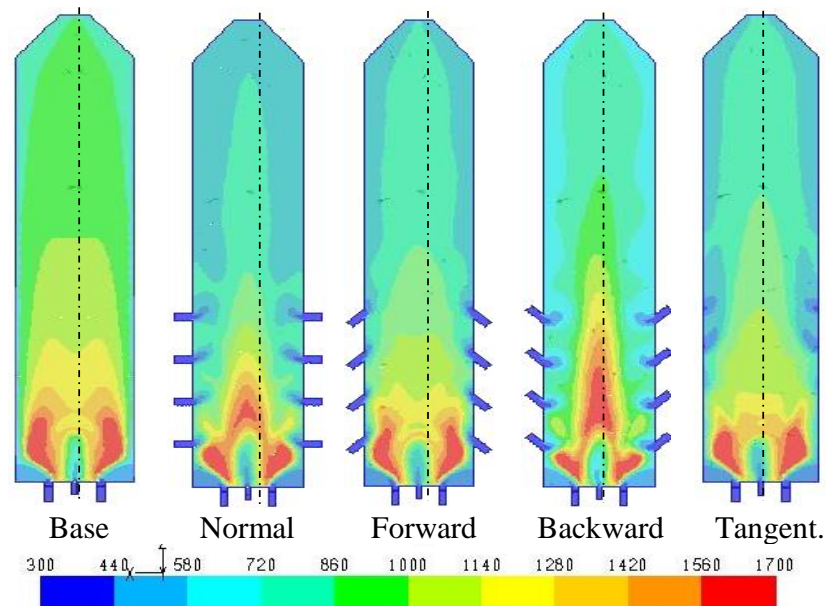

Tangent.

Fig. 10 Effect of secondary air direction on temperature. maps from calculations $[\mathrm{S}=\mathbf{0 . 8 7}$ and $\mathrm{A} / \mathrm{F}=\mathbf{5 0}$ and $\mathrm{SPAR}=1$ ]

The high temperature region is found at $0.2 \leq \mathrm{x} / \mathrm{D} \leq 1$, $0.2 \leq \mathrm{x} / \mathrm{D} \leq 0.75, \quad 0.2 \leq \mathrm{x} / \mathrm{D} \leq 1, \quad 0.1 \leq \mathrm{x} / \mathrm{D} \leq 0.75$ for normal, forward, backward and tangential directions, respectively. For normal and backward directions the high temperature regions have larger size than that for forward and tangential directions.

The flame is very compact for normal, forward and tangential directions and it is relatively long and its diameter is narrow for backward direction. There is a decrease in the flame diameter due to the restriction effect of the backward direction. For tangential direction, the temperature levels become shorter in length but wider in diameter as shown in Fig. 10. For normal and backward directions, the flame diameter decreases but for backward the flames length increases remarkably For forward and tangential secondary air, the flame diameter is increased upstream but decreased downstream because of the swirling effect and the forward flow of the secondary air.

\subsection{Visible Flame Length}

In general, reducing the flame size leads to minimizing the combustor size. In the present study, the flame length is measured visibly through the measuring ports located axially along the combustor axis. The effect of secondary air direction on the flame length for $\mathrm{A} / \mathrm{F}$ of 40 and different swirl numbers [SPAR=1] is shown in Fig. 11 . Introducing the secondary air leads to decreasing the flame length as a result of dilution. Among all cases, the shortest flame length is obtained in case of tangential direction due to the high swirling effect. The backward direction gives the longest flame length which can be increased above the base case at other conditions. 
The effect of secondary air direction on the visible flame length for different $\mathrm{A} / \mathrm{F}$ ratios and different swirl numbers is shown in Fig. 12. This effect is more obvious at $\mathrm{A} / \mathrm{F}=50$ for all directions while the secondary air has slight effect on flame lengths particularly at weak swirl. At $\mathrm{A} / \mathrm{F}=30$ and $S=0.5$, secondary air has nearly no effect on flame length for normal and backward directions while it has slight effect on flame length for forward and tangential directions. At same $\mathrm{A} / \mathrm{F}=30$, but for $\mathrm{S}=1.5$, secondary air has an obvious effect for all directions except for backward one.

For A//F ratio of 50 (small size flame), Secondary air leads to an increase of flame length for backward direction at both weak and strong swirl. At strong swirl, secondary air leads to a decrease in flame length except for backward direction where it leads to an increase in the flame length. In case of short flame and strong swirl, the tangential direction has the shortest flame length due to the high swirl effect as shown in Fig 12. For $\mathrm{A} / \mathrm{F}=50$ and $\mathrm{S}=0.87$, the flame length is decreased by about $20 \%, 30 \%$ and $40 \%$ for normal, forward and tangential directions, respectively, while it is increased by about $25 \%$ for backward direction.

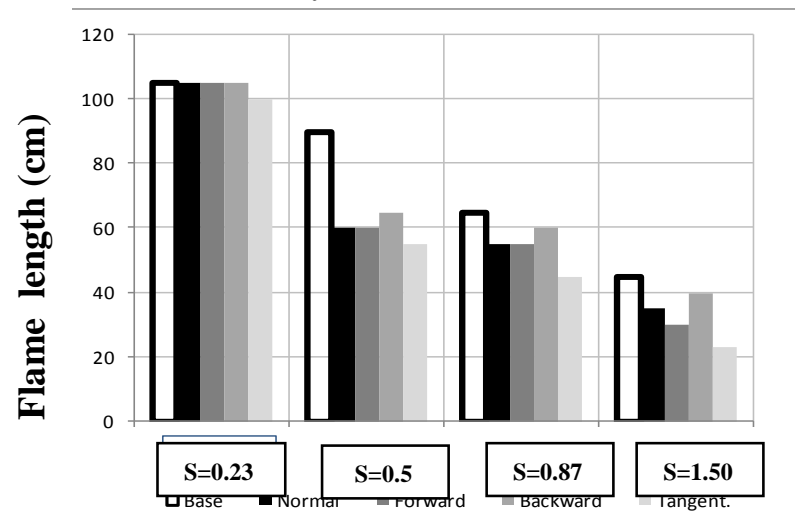

Fig. 11 Effect of secondary air directions on the visible flame length for different swirl numbers $[\mathrm{A} / \mathrm{F}=\mathbf{4 0} \& \mathrm{SPAR}=1]$

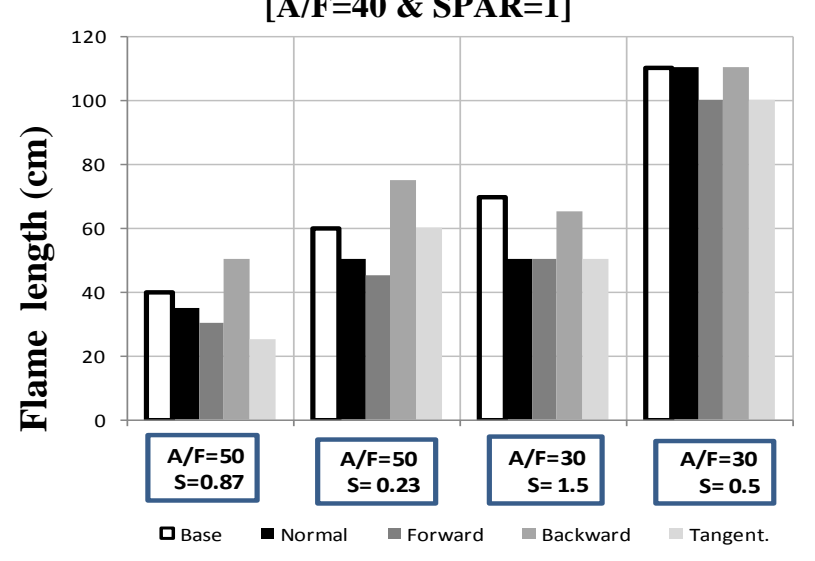

Fig. 12 Effect of secondary air direction on visible flame length for different $\mathrm{A} / \mathrm{F}$ ratios and different swirl numbers $[$ SPAR $=1]$

\subsection{Centerline Species Concentrations}

From computations using Fluent 6.3, the effect of secondary air direction on the exhaust species concentrations is presented in this section. The species concentrations from computational results include: $\mathrm{O}_{2} \mathrm{CO}$, and $\mathrm{CO}_{2}$ concentrations along the combustor centerline. The effect of secondary air direction for air/fuel ratio of 50 at swirl numbers of $0.23,1.5$ [SPAR=1] is shown in Figs. 13 and 14, respectively. For the case without using secondary air, the $\mathrm{O}_{2}$ concentration decreased by about 40 $\%$ at the combustor exit as the swirl number increases from 0.23 to 1.5. Introducing secondary air, the $\mathrm{O}_{2}$ concentrations decreased at upstream portion of the combustor except for forward direction and they increase with a further axial distance at $\mathrm{S}=0.23$. The high value of $\mathrm{O}_{2}$ concentrations are found for normal and forward directions and they have low values for backward and tangential ones. At $\mathrm{S}=1.5$ the high values of $\mathrm{O}_{2}$ occur for forward, normal and tangential directions (at the downstream portion of the combustor) due to the decrease in the flame size. The lower values of $\mathrm{O}_{2}$ concentration is found for backward direction.

Increasing the swirl number, the levels of $\mathrm{CO}$ concentrations decrease and move upstream. Introducing the secondary air leads an increase $\mathrm{CO}$ concentrations for both the weak and strong swirl and for all directions. The higher level of $\mathrm{CO}$ occurs with the backward direction at $\mathrm{S}=0.23$ and for both backward and normal directions at $\mathrm{S}=1.5$ while the lower level occurs for the forward one for both swirl numbers. For $\mathrm{S}=0.23$, the maximum value of $\mathrm{CO}$ is decreased below that of the case of backward direction by about $15 \%, 18 \%, 50 \%$ for normal, tangential and forward directions, respectively

Introducing secondary air leads to a decrease in the $\mathrm{CO}_{2}$ concentration for normal and forward directions at weak swirl while at strong swirl this reduction occurs for normal, forward and tangential directions. Backward direction has higher levels of $\mathrm{CO}_{2}$ at both weak and strong swirl. For $\mathrm{S}=0.23, \mathrm{CO}_{2}$ for backward and tangential directions increase at the first portion and decrease at the second portion of the combustor. For $\mathrm{S}=1.5, \mathrm{CO} 2$ for normal and backward increases in the first portion and then decrease in the second portion of the combustor. Introducing secondary air leads to $\mathrm{CO}_{2}$ reduction by about $50 \%$ for forward and normal directions at the combustor exit for $\mathrm{S}=0.23$. At $\mathrm{S}=1.5$, the backward direction has higher $\mathrm{CO}_{2}$ along the combustor and at its exit. At combustor exit backward direction cause a reduction of $\mathrm{CO}_{2}$ of about $30 \%$ while $\mathrm{CO} 2$ is reduced by $50 \%$ for other directions at $\mathrm{S}=1.5$. 

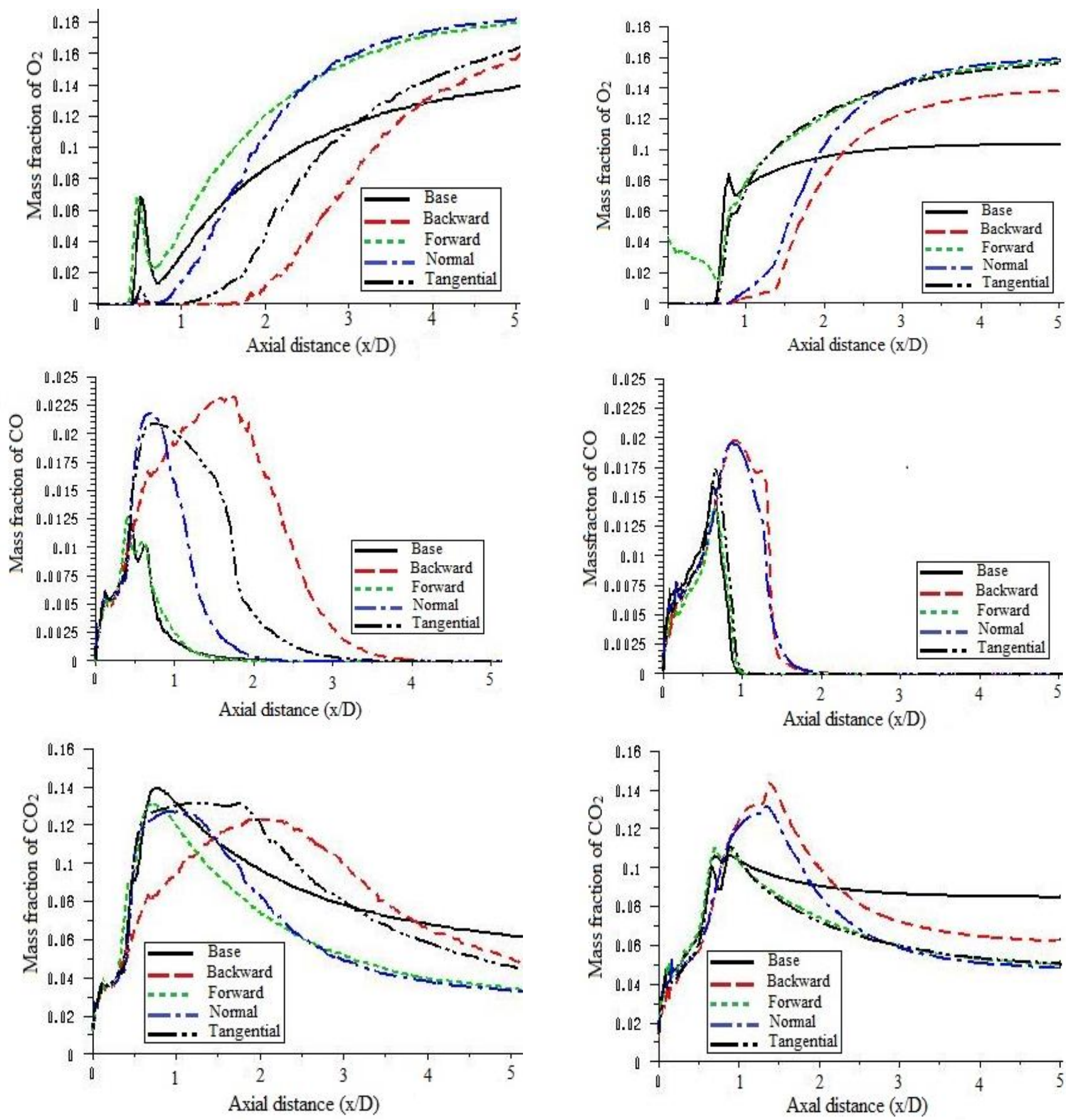

Fig.13 Effect of secondary air direction on centerline species concentrations for swirl number of 0.23 and $A / F$ ratio of 50 [SPAR=1 \& Calculated]

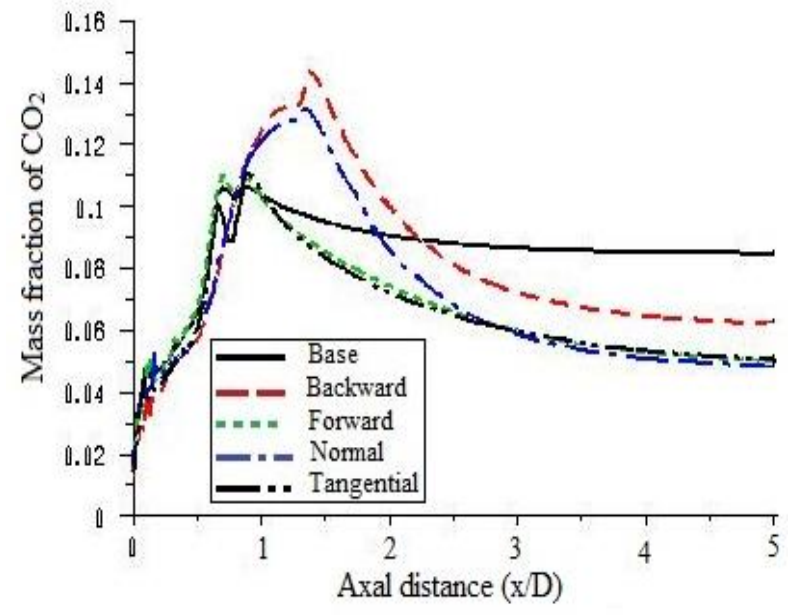

Fig. 14 Effect of secondary air direction on centerline species concentrations for swirl number of 1.5 and $A / F$ ratio of 50 [SPAR $=1 \&$ calculated] 


\section{CONCLUSIONS}

From both the experimental and computational results, the following conclusions are obtained:

1 Comparison between the measured and the calculated temperatures was found to be in good agreement

2 For large size flame, secondary air affect the flame diameter remarkably while it has slight effect on flame length .

3 For small size flame, secondary air leads to a decreased in flame size. For weak swirl the effect is more clear on flame diameter while for strong swirl secondary air affect the flame length and diameter for all directions. There are remarkable changes in flame sizes due to the effect of all directions in this case.

4 In normal, forward and tangential directions, the flame length is decreased by introducing secondary air but it is increased for backward direction. The tangential direction gives the smallest flame sizes for most cases.

5 In case of tangential secondary air, the flame is short and wide and this may be due to its swirling effect while normal direction gives narrow flame diameter.

6 The flame is very compact for normal, forward and tangential and its length is relatively long for backward. The backward direction gives the longest flame with the smallest diameter due to the restriction effect of the backward direction.

7 Backward direction gives lower $\mathrm{O}_{2}$ concentrations and higher $\mathrm{CO}$ and $\mathrm{CO}_{2}$. concentrations while normal and forward directions give higher $\mathrm{O}_{2}$ and lower $\mathrm{CO}$ and $\mathrm{CO}_{2}$ concentrations.

\section{REFERENCES}

[1] Goebel, S. G., Abauf, N., Lovett, J. A., and Lee, C. P., 1993, "Measurements of Combustor Velocity and Turbulence Profiles," ASME Paper No. 93GT-228.v

[2] Crocker, D. S., Smith, C. E., and Myers, G. D., 1994, "Pattern Factor Reduction in a Reverse Flow Gas Turbine Combustor Using Angled Dilution Jets," ASME Paper No. 94-GT-406.v

[3] Li L., Peng X. F. and, liu T. "combustion and cooling performance in an aero-engine annular combustor", applied thermal engineering 26 (2006) 1771-1779

[4] Beer J.M. and Chigier N.A," Combustion Aerodynamics", Applied Science Publisher, London, 1972.

[5] Syred N., Beer J.M., "Combustion in swirling flows: a review”, Combustion and Flame 23 (1974) 143-201.

[6] Sloan D.J., Smith P.J and Smoot L.D. "Modelling of swirl in turbulent flow system", Prog. Energy Combust. Sci 12 (1986) 163-250.

[7] Chigier, N.A., Progress in Energy and Combustion Science, 4, Oxford, Pergamon Press, 1987UK.

[8] Claypole, T.C. and Syred, N., " The Effect of Swirl Burner Aerodynamics on NOx formation"

Eighteenth International Symposium on Combustion, 1981, 8, 81-89.

[9] German A and Mahmud T. Modelling of nonpremixed swirl burner flows using a Reynoldsstress turbulence closure. Fuel 2005;84:583-594.

[10] Jones WP and Kakhi M. "Pdf modeling of finiterate chemistry effects in turbulent non-premixed jet flames". Combust Flame 1998;115:210-29.

[11] Gad H. M., Farag T. M., Abdel-Mageed S. I., Habik S. E. and Ezz-Eldien A. H., "Kerosene Spray Combustion Characteristics in a Swirl Type Combustor with Normal Secondary Air", Port-Said Engineering Research Journal Faculty of Engineering Port Said University Volume 14, No. 2, September 2010, pp. 52 - 66

[12] Abou-Arab T. W., Salem H. and Elkotb M.M., "Factors affecting the performance of a 2-D natural gas combustor model" 1552 FUEL, 1990, Vol 69

[13] Ko T. H. "A numerical study on the effects of sideinlet angle on the mixing phenomena in a threedimensional side-dump combustor, international Communications in Heat and Mass Transfer 33 (2006) 853-862

[14] Gad H. M., Farag T. M., Abdel-Mageed S. I., Habik S. E. and Ezz-Eldien A. H. "Effect of Secondary Air Direction on the Kerosene Spray Combustion Characteristics", Port-Said Engineering Research Journal, Volume 14, No. 2, September 2010, pp. 41 - 51

[15] Falcitelli M., Pasini S. and Tognotti L., "Modelling practical combustion systems and predicting NOx emissions with an integrated CFD based approach", Computers and Chemical Engineering 26 (2002) 1171-1183

[16] Fluent Program User Guide, September (2007).

[17] Gambit Program User Guide, September (2007).

[18] Farag T. M., " A study of atomized premixed flame structure", M. Sc.thesis, Cairo university 1977

[19] Fawzy El-Mahallawy and Saad El-Din Habic "Fundamental and technology of combustion", El Sevier Science Ltd First edition 2002 